\title{
Analysis of Cost and Utilization of Health Care Services Before and After Initiation of Insulin Therapy in Patients With Type 2 Diabetes Mellitus
}

\author{
MICHAEL S. ROSENBLUM, PharmD, MBA, and MICHAEL P. KANE, PharmD, BCPS
}

\begin{abstract}
OBJECTIVE: This study analyzed the cost and utilization of health care services before and after the initiation of insulin in treating patients with type 2 diabetes mellitus (DM) to determine if disease-related and total health care costs decreased after patients were started on insulin therapy.
\end{abstract}

METHODS: 1,177 patients with type 2 DM between the ages of 18 and 65 years and continuously enrolled in a managed care organization for 9 months before and after their insulin start date were included in the study. Medical, facility, and pharmaceutical services in the preinsulin and postinsulin time period were examined along with a subanalysis of all types of medical service categories. Trending analysis was performed by dividing the postinsulin time period into mutually exclusive 2-month periods. The cost of total and disease-related services were studied over these intervals.

RESULTS: Analysis of the total 9-month preinsulin and 9-month postinsulin periods determined that average total and disease-related costs increased after insulin was started, with a mean difference of $\$ 2,220(P<0.001)$ for average total costs and $\$ 430(P<0.001)$ for disease-related costs. Trending analysis, though, demonstrated that much of the cost increase after the start of insulin occurred in the initial 2-month postinsulin period, after which both total costs and diseaserelated costs decreased by $57 \%(P<0.001)$ and $49 \%(P<0.001)$, respectively, throughout the remainder of the postinsulin time period. Facility costs decreased at all postinsulin measurement intervals, while pharmacy costs were the only treatment component to remain above the preinsulin period. Pharmacy services accounted for a greater proportion of the costs in treating patients with type 2 DM in the postinsulin time period, increasing from $19.8 \%$ of costs at baseline to $42.8 \%$ at postinsulin months 6 to 8 .

CONCLUSION: The initiation of insulin therapy in the management of type $2 \mathrm{DM}$ involves an approximate $10 \%$ increase in total health care expenditures initially, although this is offset by the consistent and substantial $40 \%$ decrease in subsequent total health care expenditures 9 months following insulin initiation.

KEYWORDS: Type 2 diabetes mellitus, Cost and utilization analysis, Administrative claims data, Insulin, Retrospective cohort analysis

J Managed Care Pharm. 2003;9(4):309-16
T he cost and utilization of health care services in the United States have demonstrated continued annual increases, with an estimated $\$ 1.3$ trillion total national health care expenditure in 2000 , including $\$ 175$ billion on prescription drugs. ${ }^{1}$ Diabetes mellitus (DM) is representative of this phenomenon. The prevalence of diabetes increased by approximately $40 \%$ during the $1990 \mathrm{~s}^{2}$ and currently afflicts an estimated 16 million Americans, 95\% of whom have type 2 DM. ${ }^{3}$

Therapeutic choices for treating DM have continued to evolve, with 12 new drugs, including 3 new insulin analogs and 4 new classes of drugs, becoming available within the last 8 years. Prescription medications is the fastest growing sector by expenditure among health-related services in the United States, ${ }^{1}$ but spending on prescription drugs can be cost effective. ${ }^{4-6}$

Diabetes mellitus is associated with significant human and economic burdens. Diabetes is the leading cause of adult-onset blindness, end-stage renal disease, and nontraumatic amputation and is a major contributor to cardiovascular disease. ${ }^{7,8}$ Approximately $50 \%$ of type $2 \mathrm{DM}$ patients have diabetes-associated complications at the time of diagnosis. ${ }^{9}$ The economic cost of diabetes in 2002 was estimated at $\$ 132$ billion, with an estimated $\$ 92$ billion in direct costs..$^{10}$ Much of the direct costs of diabetes is associated with the inpatient treatment of diabetesrelated complications. Patients with diabetes have per capita medical expenses almost two-and-a-half times higher than their nondiabetic counterparts. ${ }^{11}$

Most patients with type 2 DM eventually fail oral therapy, requiring insulin therapy for disease management. Initially, about one third of patients with type $2 \mathrm{DM}$ require insulin injections to manage their disease. The long-term need for insulin in patients with type $2 \mathrm{DM}$ is even greater since the use of sulfonylurea and metformin therapy is associated with an approximate $20 \%$ to $25 \%$ primary failure rate and a secondary failure rate of $5 \%$ to $7 \%$ per year.

In the United Kingdom Prospective Diabetes Study, at 9 years, fewer than $25 \%$ of patients receiving a sulfonylurea or metformin were adequately controlled (i.e., fasting blood glucose $<140 \mathrm{mg} / \mathrm{dL}$ or hemoglobin AlC $<7 \%) .{ }^{12-14}$ Due to factors such as increased risk of severe hypoglycemic episodes, the need to teach patients appropriate insulin use techniques, concern of weight gain, and concerns of the possible exacerbation of hyperinsulinemia and the dysmetabolic syndrome, ${ }^{15}$ patients and clinicians are often reluctant to initiate insulin therapy despite the success of insulin in significantly improving glycemic control 


\section{Analysis of Cost and Utilization of Health Care Services Before and After Initiation of Insulin Therapy in Patients With Type 2 Diabetes Mellitus}

\begin{tabular}{|c|c|}
\hline \multicolumn{2}{|r|}{ ICD-9-CM Code Reference } \\
\hline$\overline{\text { Code }}$ & Description \\
\hline 250 & Diabetes mellitus \\
\hline $250 . x 0$ & $\begin{array}{l}\text { Diabetes mellitus type } 2 \text { or unspecified type, } \\
\text { not stated as uncontrolled }\end{array}$ \\
\hline $250 . x 1$ & Diabetes mellitus type 1 , not stated as uncontrolled \\
\hline $250 . x 2$ & $\begin{array}{l}\text { Diabetes mellitus type } 2 \text { or unspecified type, } \\
\text { uncontrolled }\end{array}$ \\
\hline $250 . x 3$ & Diabetes mellitus type 1 , uncontrolled \\
\hline \multicolumn{2}{|c|}{ Generic Product Identifier (GPI)* Code Reference } \\
\hline Code & Description \\
\hline 2710 & Insulin \\
\hline 2720 & Sulfonylureas \\
\hline 2723 & Antidiabetic-amino acid derivatives \\
\hline 2725 & Biguanides \\
\hline 2728 & Meglitinide analogues \\
\hline 2730 & Miscellaneous diabetic agents \\
\hline 2750 & Alpha-glucosidase inhibitors \\
\hline 2760 & Insulin sensitizing agents \\
\hline 2799 & Antidiabetic combinations \\
\hline 9720 & Diabetic supplies \\
\hline \multicolumn{2}{|c|}{$\begin{array}{l}\text { * The Generic Product Identifier (GPI-Medispan)=first } 4 \text { characters of the } \\
\text { 14-character number [http://www.medispan.com/products/product_mddb.asp; } \\
\text { accessed April 30, 2003]. }\end{array}$} \\
\hline
\end{tabular}

in patients failing oral therapy ${ }^{16}$ This study compared the utilization and costs associated with diabetes-related health care services and total health care services before and after the initiation of insulin therapy in patients with type $2 \mathrm{DM}$.

\section{Methods}

Using administrative claims data, a retrospective cohort analysis was performed of the cost and utilization of health care services for patients with type $2 \mathrm{DM}$ who were started on insulin. Two study perspectives were employed in this project: (1) an overall aggregate analysis using the entire preinsulin and postinsulin period as the time unit for the study, and (2) a postinsulin trending analysis. Short-term was defined as the 2-month time period immediately after the initiation of insulin and long-term defined as the 6- to 8-month period following insulin start.

\section{Data Sources and Study Population}

The study population was identified from a managed care database of 12,663,986 members with both medical and pharmacy claims data during a 4-year period between January 1, 1997, and December 31, 2000. The database included medical and pharmacy claims, demographic markers (such as age, gender, and geographic region), provider information (primary care, specialty care, and place of service), and member eligibility, the latter being critical to determining continuous enrollment status. The following inclusion criteria were applied to the entire population to identify the subset of patients with type $2 \mathrm{DM}$ (ICD-9 CM and Generic Product Identifier [GPI: first 4 characters of the 14-character identifier] codes defined in Table 1):

- ICD-9-CM 250, 250.x, 250.x0, or 250.x2 exclusively in the database (excludes 250.x1 and 250.x3 codes); or

- ICD-9-CM 250.xx with at least 2 prescriptions from the following GPI drug classes: 2720, 2723, 2725, 2728, 2730, 2750, 2760, 2799; or

- ICD-9-CM 250.xx with no antidiabetic pharmacotherapy; or

- Members with 2 or more prescriptions for oral antidiabetic drug therapy with no ICD-9-CM criteria.

Following the identification of patients with type $2 \mathrm{DM}$ in the overall data set, the final study sample was defined from this population based on the following criteria:

- patients between the ages of 18 and 65 years,

- insulin initiated as part of the patient's drug therapy,

- eligible in the database for 9 months before and after insulin initiation (18 months of total continuous enrollment),

- treatment with oral antidiabetic medications before insulin initiation, and

- patient health coverage included medical and pharmacy benefits during the entire database eligibility period.

This population was subsequently used for data comparison and analysis. The following exclusion criteria were applied:

- members not continuously enrolled in the database,

- members with an ICD-9 CM diagnosis of 250 and receiving insulin exclusively,

- members with ICD-9 CM diagnosis of 250.x1 and/or 250.x3 (type $1 \mathrm{DM}$ ) exclusively, and

- members without medical and pharmacy benefits during their database eligibility.

The Hierarchical Coexisting Condition model, a diagnosisbased risk-assessment model, was used to identify patient comorbidities ${ }^{17}$ Multiple regression analysis was performed using the identified comorbidities, patient age, gender, and region to evaluate the statistical power of these variables in explaining the differences in costs before and after the start of insulin.

\section{Pricing Standardization}

Medical and pharmacy costs were standardized across health plans. For professional and ancillary services, a uniform fee schedule was applied based on the resource-based relative value scale. ${ }^{18}$ Facility inpatient service pricing was based on an estimated per diem cost, taking into account the diagnostic service category of the facility, the presence of a major surgery, the presence of an ICU stay, and the length of stay. Inpatient price stan- 


\section{Analysis of Cost and Utilization of Health Care Services Before and After Initiation of Insulin Therapy in Patients With Type 2 Diabetes Mellitus}

dardization was calculated to control for variations in inpatient reimbursement found among health plans. Pharmacy pricing was based on an average payment schedule using observed payments (plan payment amount after subtraction of prescription copayments) per unit of metric quantity in the database. For example, the average plan payment amount per unit for each medication was calculated and applied across the database in order to avoid any biases created with different benefit designs or pharmacy contracts.

\section{Data Analysis and Measures}

Utilizing insulin initiation as the defined trigger event, patients with type 2 DM with 9 months of continuous enrollment in the dataset before and after the trigger event were identified. Analyses of overall costs and utilization of and overall health care services during preinsulin and postinsulin 9-month time periods were performed. Measures included medical, pharmacy, and confinement (defined as inpatient facility) costs, with the insulin trigger event included in the postinsulin pharmacy category. Services provided to the study cohort were assigned to one of 29 mutually exclusive types of services (TOS) categories. Results are reported for unadjusted and truncated costs. Truncation was employed to examine the effect of outlier cases on average costs and was set at 3 standard deviations from the mean. Any costs that exceeded 3 standard deviations from the mean were truncated at that level. Aggregate costs and utilization before and after insulin initiation were compared, along with performance of a postinsulin costtrending analysis. The aggregate cost and utilization analysis included the entire 9-month preinsulin and postinsulin time period (18 months in total). The trending analysis evaluated the costs of health care services in 60-day periods in months 0 to 2, 2 to 4 , 4 to 6 , and 6 to 8 after insulin initiation, compared to the 2-month preinsulin period. The final 30 days of month 9 were not included in the trending analysis since all comparisons were performed using mutually exclusive 60-day periods.

Diabetes-related drugs were identified using the Medispan 14-character GPI coding system. Medications with a GPI starting with "27" (representing the drug group category of antidiabetic agents of the 14-character code) were classified as antidiabetic drugs and included in the disease-related category, as were diabetic supplies with a GPI starting with 9720 (representing the drug class of diabetic supplies). Diabetes-related medical costs were defined as all medical claims associated with an ICD-9 CM diagnosis code of 250. All confinements in which the discharge diagnosis was 250 were considered disease-related for the purpose of this study. All other confinements in which the admission diagnosis or any documented facility diagnosis during the admission was 250 were reviewed to determine if the facility cost was diabetes-related.

\section{Statistical Analyses}

Comparisons of cost and procedure utilization were analyzed using paired $t$ tests and calculated using the PRT option of

\section{TABLE $2 \longdiv { \text { Population Demographics } }$}

\begin{tabular}{|c|c|c|c|r|r|}
\cline { 3 - 6 } \multicolumn{2}{c|}{} & \multicolumn{2}{c|}{ Type 2 DM Cohort (215,024) } & \multicolumn{2}{c|}{ Study Cohort (1,177) } \\
\cline { 3 - 6 } \multicolumn{2}{c|}{} & Male (\%) & Female (\%) & Male (\%) & Female (\%) \\
\hline \multirow{4}{*}{$\begin{array}{c}\text { Age } \\
\text { Group }\end{array}$} & $18-25$ & $1,274(0.6)$ & $2,359(1.1)$ & $3(0.3)$ & $7(0.6)$ \\
\cline { 2 - 6 } & $26-40$ & $17,402(8.1)$ & $21,417(10.0)$ & $71(6.0)$ & $96(8.2)$ \\
\cline { 2 - 6 } & $41-55$ & $57,200(26.6)$ & $48,641(22.6)$ & $305(25.9)$ & $284(24.1)$ \\
\cline { 2 - 6 } & $56-65$ & $38,007(17.7)$ & $28,724(13.3)$ & $227(19.3)$ & $184(15.6)$ \\
\cline { 2 - 6 } & Total & $113,883(53)$ & $101,141(47)$ & $606(51.5)$ & $571(48.5)$ \\
\hline
\end{tabular}

PROC MEANS in SAS version $8 .{ }^{19}$ Statistical significance was set at $P \leq 0.05$. Multiple regression analysis was performed to test for differences in cost using patient comorbidities, age, gender, and geographic region as variables.

\section{Results}

The study identified 215,024 patients (1.7\%) of the overall database as having type $2 \mathrm{DM}$, of which 1,177 patients $(0.5 \%$ of the patients with type 2 diabetes) met all study eligibility criteria. Patients' age, gender, and geographic region were similar for both cohorts (Table 2). Of the 9 geographic regions, the Pacific region had the lowest representation in the data set ( $1.7 \%$ in the overall type $2 \mathrm{DM}$ cohort and $0.6 \%$ in the study cohort), primarily due to the high degree of capitation financing of medical services in the marketplace and the resulting poor capture of medical claims associated with this managed care operational model. The Middle Atlantic, New England, and South Atlantic regions accounted for $65 \%$ of the study cohort. The comorbidities most prevalent in the study population included cardiovascular disease (55.7\%), musculoskeletal-connective tissue conditions (41.5\%), endocrine and metabolic disease other than diabetes (39.1\%), and minor dermatological disorders (29.1\%).

\section{Disease-related and Total Costs and Utilization}

Pharmacy and medical costs were measured over the entire 9-month preinsulin and postinsulin time period, resulting in an 18-month longitudinal analysis. Disease-related and total pharmacy and medical costs increased in the aggregated 9-month period after insulin initiation compared to the 9-month period prior to insulin use (Table 3). The mean increase in diseaserelated pharmacy and medical costs were $\$ 144(P<0.001)$ and $\$ 258(P<0.001)$, respectively. Disease-related and total facility costs were not statistically different during these periods. Overall disease-related and total costs increased by a mean of $\$ 430(P<0.001)$ and $\$ 2,220(P<0.001)$, respectively. Mean differences in disease-related and total truncated costs were less than the unadjusted data, but remained statistically significant.

The overall increase in medications and prescriptions filled 


\section{Analysis of Cost and Utilization of Health Care Services Before and After Initiation of Insulin Therapy in Patients With Type 2 Diabetes Mellitus}

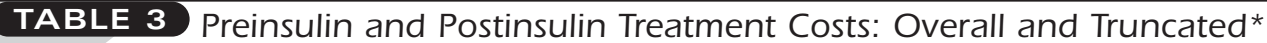

\begin{tabular}{|c|c|c|c|c|c|c|}
\hline Differences in: & & $\begin{array}{c}\text { Preinsulin } \\
\text { Mean Cost }(\$)\end{array}$ & $\begin{array}{c}\text { Postinsulin } \\
\text { Mean Cost (\$) }\end{array}$ & $\begin{array}{c}\text { Mean } \\
\text { Difference (\$) }\end{array}$ & $\begin{array}{l}\text { Standard Deviation } \\
\text { of Differences }\end{array}$ & $P$ Value \\
\hline \multirow[t]{2}{*}{ Pharmacy costs: disease-related } & Truncated & 508 & 652 & 144 & 504 & $<0.001$ \\
\hline & Untruncated & 501 & 644 & 143 & 492 & $<0.001$ \\
\hline \multirow[t]{2}{*}{ Pharmacy costs: total } & Truncated & 1,431 & 2,008 & 577 & 1,349 & $<0.001$ \\
\hline & Untruncated & 1,377 & 1,936 & 559 & 1,034 & $<0.001$ \\
\hline \multirow[t]{2}{*}{ Medical costs: disease-related } & Truncated & 685 & 943 & 258 & 2,432 & $<0.001$ \\
\hline & Untruncated & 625 & 831 & 205 & 1,395 & $<0.001$ \\
\hline \multirow[t]{2}{*}{ Medical costs: total } & Truncated & 2,880 & 4,073 & 1,193 & 8,207 & $<0.001$ \\
\hline & Untruncated & 2,591 & 3,450 & 859 & 5,279 & $<0.001$ \\
\hline \multirow[t]{2}{*}{ Facility costs: disease-related } & Truncated & 286 & 314 & 28 & 3,072 & NS \\
\hline & Untruncated & 156 & 163 & 6 & 1,572 & NS \\
\hline \multirow[t]{2}{*}{ Facility costs: total } & Truncated & 3,518 & 3,967 & 450 & 15,959 & NS \\
\hline & Untruncated & 2,882 & 3,208 & 326 & 11,260 & NS \\
\hline \multirow[t]{2}{*}{ Total costs: disease-related } & Truncated & 1,480 & 1,910 & 430 & 4,100 & $<0.001$ \\
\hline & Untruncated & 1,340 & $1,696.70$ & 357.04 & 2,515 & $<0.001$ \\
\hline \multirow[t]{2}{*}{ Total costs: total } & Truncated & 7,828 & 10,048 & 2220 & 19,168 & $<0.001$ \\
\hline & Untruncated & 7,043 & 8,947 & 1,904 & 14,458 & $<0.001$ \\
\hline Distinct drugs & & 2.00 & 2.80 & 0.80 & 1.25 & $<0.001$ \\
\hline Number of prescriptions & & 9.56 & 12.50 & 2.94 & 6.55 & $<0.001$ \\
\hline
\end{tabular}

between the preinsulin and postinsulin time periods were also statistically significant $(P<0.001)$. This is consistent with the results for the disease-related and overall pharmacy costs in both measurement periods.

Table 4 shows the comparison of preinsulin and postinsulin cost and utilization of the TOS categories for the total and disease-related analysis, including average differences in procedure utilization and costs. These results were calculated during the 9-month preinsulin and postinsulin analytic time period. Statistically significant increases in disease-related cost and utilization were found in the ancillary service categories of home health/hospice visits and services and supplies, while increases in drug utilization were found in the total health care service analysis. Office visits increased in the disease and total health care service categories, as did laboratory; obstetrics; physical medicine; radiology; and vision, hearing, and speech exams, while facility costs were unchanged.

\section{Trending Costs}

Table 5 compares disease-related and total health care expenditures preinsulin and postinsulin therapy. Average pharmacy, medical, facility, and total disease-related costs during the 2-month time period prior to insulin use were $\$ 125, \$ 256$, $\$ 250$, and $\$ 631$, respectively. Increases in pharmacy, medical, and total costs were noted in the 2-month period immediately after insulin initiation, although only increases in pharmacy costs were statistically significant $(P<0.001)$. These cost increases began to reverse in postinsulin months 2 to 4 , and fell below the preinsulin levels by months 4 to 6 in all categories except pharmacy. Facility costs decreased in all measurement periods. At months 4 to 6 , medical $(P=0.003)$, facility $(P=0.013)$, and total costs $(P=0.002)$ were all significantly below those of the 2-month preinsulin time period.

Comparisons of postinsulin measures at various 2-month intervals demonstrate a consistent decrease in most cost categories as a patient moved out from the insulin trigger event. Pharmacy costs were the only component cost to remain above that of the preinsulin time period, increasing from $19.8 \%$ of total costs at baseline to $42.8 \%$ at postinsulin months 6 to 8 .

The results for total costs parallel those for the disease-related category, with costs increasing in the initial 2-month period postinsulin initiation, then decreasing in the subsequent 2-month periods (Table 5). In the preinsulin period, pharmacy, medical, and facility components accounted for $10.5 \%, 28.0 \%$, 


\section{Analysis of Cost and Utilization of Health Care Services Before and After}

Initiation of Insulin Therapy in Patients With Type 2 Diabetes Mellitus

\section{TABLE 4 Utilization and Cost: Mean Differences Preinsulin and Postinsulin*}

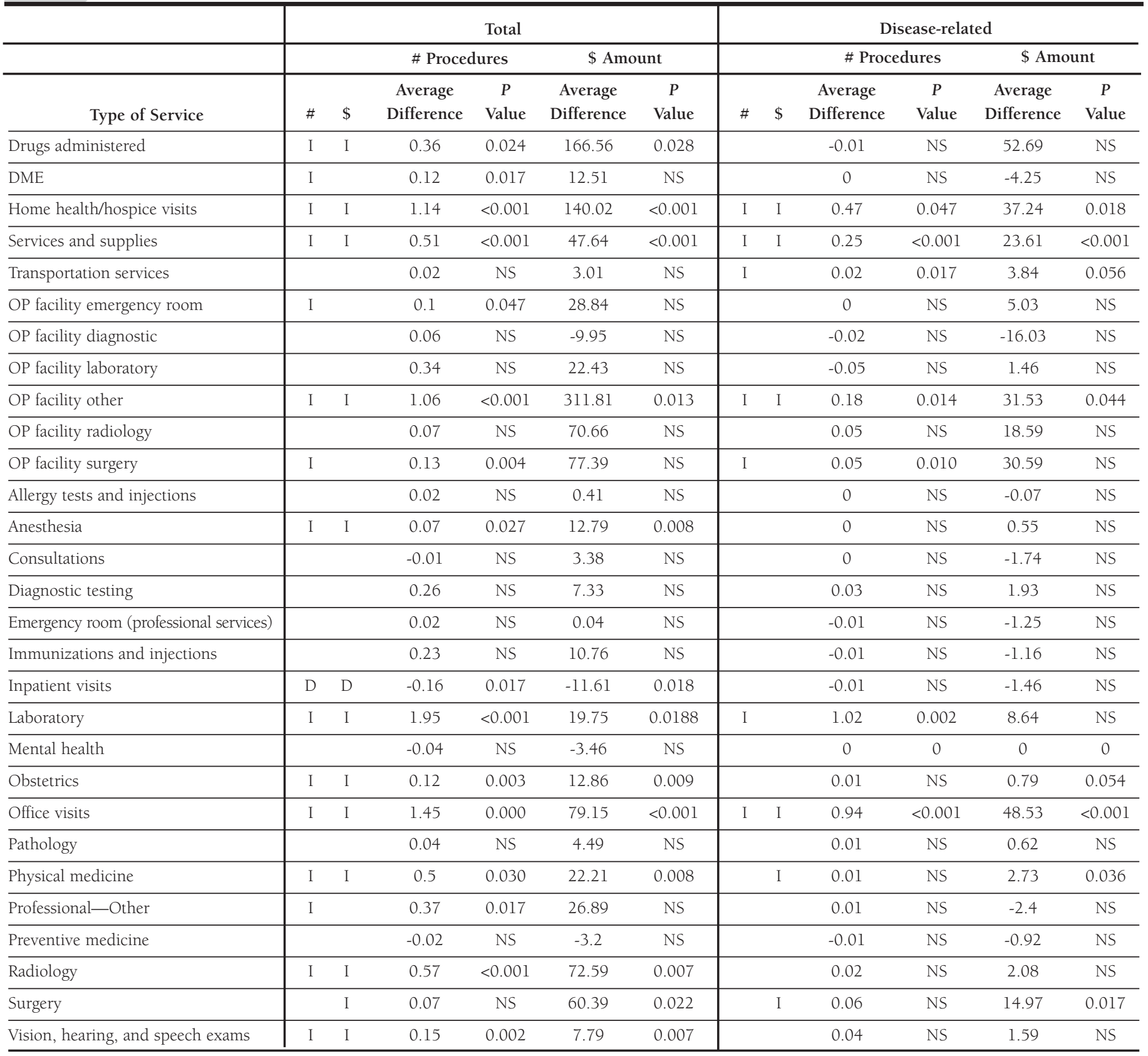

*Results derived for the 9-month preinsulin and 9-month postinsulin study periods. $I=$ Increase; $D=$ Decrease $(P \leq 0.05)$.

and $61.5 \%$ of the overall total costs. This compares to $22.6 \%$, $42.5 \%$, and $34.9 \%$ at postinsulin months 6 to 8 . Medical, facility, and total costs all decreased to levels below the 2-month preinsulin measurement period by months 2 to 4 , while pharmacy costs continued to remain at levels above the preinsulin measurement period.

\section{Discussion}

The results of this study demonstrate that while the total health care costs of patients with type 2 DM initially increase when insulin therapy is started, insulin use is associated with an overall decrease in long-term health care expenditures. The initial increase in health care costs was primarily due to an increase in 


\section{Analysis of Cost and Utilization of Health Care Services Before and After Initiation of Insulin Therapy in Patients With Type 2 Diabetes Mellitus}

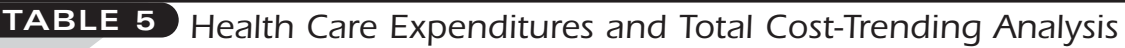

\begin{tabular}{|c|c|c|c|c|c|c|c|c|}
\hline \multirow[b]{3}{*}{ Comparison } & \multicolumn{8}{|c|}{ Disease-related Expenditures: Difference in Average Costs $(\$)^{*}$} \\
\hline & \multicolumn{2}{|l|}{$\mathrm{Rx}$} & \multicolumn{2}{|l|}{ Medical } & \multicolumn{2}{|l|}{ Facility } & \multicolumn{2}{|l|}{ Total } \\
\hline & $\begin{array}{l}\text { Difference } \\
\text { (Average) }\end{array}$ & $P$ Value & $\begin{array}{l}\text { Difference } \\
\text { (Average) }\end{array}$ & $P$ Value & $\begin{array}{l}\text { Difference } \\
\text { (Average) }\end{array}$ & $P$ Value & $\begin{array}{l}\text { Difference } \\
\text { (Average) }\end{array}$ & $P$ Value \\
\hline 2-months prior with: & $(125.00)$ & & $(256.25)$ & & $(250.05)$ & & $(631.29)$ & \\
\hline $0-2$ months after & $51.24(176.24)$ & $<0.001$ & $49.45(305.69)$ & NS & $-50.52(199.53)$ & NS & $50.17(681.46)$ & NS \\
\hline 2-4 months after & $14.91(139.91)$ & $<0.001$ & $-58.97(197.28)$ & NS & $-243.38(6.68)$ & $<0.001$ & $-287.43(343.86)$ & $<0.001$ \\
\hline 4-6 months after & $11.84(136.84)$ & 0.010 & $-79.26(176.98)$ & 0.003 & $-171.09(78.96)$ & 0.013 & $-238.52(392.78)$ & 0.002 \\
\hline 6-8 months after & $17.29(142.29)$ & $<0.001$ & $-80.07(176.18)$ & $<0.001$ & $-236.07(13.98)$ & $<0.001$ & $-298.85(332.45)$ & $<0.001$ \\
\hline \multicolumn{9}{|l|}{ 0-2 months after with: } \\
\hline 2-4 months after & -36.33 & $<0.001$ & -108.42 & $<0.001$ & -192.85 & $<0.001$ & -337.60 & $<0.001$ \\
\hline 4-6 months after & -39.40 & $<0.001$ & -128.71 & $<0.001$ & -120.57 & 0.031 & -288.69 & $<0.001$ \\
\hline 6-8 months after & -33.95 & $<0.001$ & -129.52 & $<0.001$ & -185.55 & $<0.001$ & -349.02 & $<0.001$ \\
\hline \multicolumn{9}{|l|}{ 2-4 months after with: } \\
\hline 4-6 months after & -3.07 & NS & -20.30 & NS & 72.29 & NS & 48.91 & NS \\
\hline 6-8 months after & 2.38 & NS & -21.10 & NS & 7.30 & NS & -11.42 & NS \\
\hline \multicolumn{9}{|l|}{ 4-6 months after with: } \\
\hline 6-8 months after & 5.45 & NS & -.80 & NS & -64.98 & NS & -60.33 & NS \\
\hline \multicolumn{9}{|c|}{ Total Health Care Expenditures: Difference in Average Costs $(\$)^{*}$} \\
\hline 2-months prior with: & $(355.97)$ & & $(949.24)$ & & $(2,084.74)$ & & $(3,389.95)$ & \\
\hline $0-2$ months after & $163.33(519.30)$ & $<0.001$ & $211.01(1,160.25)$ & 0.002 & $-245.66(1,839.08)$ & NS & $128.67(3,518.62)$ & NS \\
\hline 2-4 months after & $67.76(423.73)$ & $<0.001$ & $-61.48(887.76)$ & NS & $-1,613.70(471.02)$ & $<0.001$ & $-1,607.50(1,782.50)$ & $<0.001$ \\
\hline 4-6 months after & $73.83(429.80)$ & $<0.001$ & $-108.56(840.67)$ & NS & $-1,449.80(634.92)$ & $<0.001$ & $-1,484.60(1,905.39)$ & $<0.001$ \\
\hline 6-8 months after & $94.99(450.96)$ & $<0.001$ & $-98.52(850.72)$ & NS & $-1,386.00(698.77)$ & $<0.001$ & $-1,389.50(2,000.44)$ & $<0.001$ \\
\hline \multicolumn{9}{|l|}{$0-2$ months after with: } \\
\hline 2-4 months after & -95.57 & $<0.001$ & -272.49 & $<0.001$ & $-1,368.10$ & $<0.001$ & $-1,736.10$ & $<0.001$ \\
\hline 4-6 months after & -89.50 & $<0.001$ & -319.57 & $<0.001$ & $-1,204.20$ & $<0.001$ & $-1,613.20$ & $<0.001$ \\
\hline 6-8 months after & -68.34 & $<0.001$ & -309.53 & $<0.001$ & $-1,140.30$ & $<0.001$ & $-1,518.20$ & $<0.001$ \\
\hline \multicolumn{9}{|l|}{ 2-4 months after with: } \\
\hline 4-6 months after & 6.07 & NS & -47.08 & NS & 163.90 & NS & 122.89 & NS \\
\hline 6-8 months after & 27.23 & 0.004 & -37.04 & NS & 227.75 & NS & 217.94 & NS \\
\hline \multicolumn{9}{|l|}{ 4-6 months after with: } \\
\hline 6-8 months after & 21.16 & 0.023 & 10.04 & NS & 63.84 & NS & 95.05 & NS \\
\hline
\end{tabular}

pharmacy and medical costs. Indeed, the number of drugs increased by $40 \%$ and the number of prescriptions increased by $31 \%$. However, starting 2 months after insulin initiation, total costs and each component cost, except pharmacy, consistently decreased.

Insulin has been utilized for more than 80 years in the management of diabetes and continues to serve as the definitive treatment of this disease despite the availability of newer pharmacologic modalities. Insulin analogs (e.g., insulin lispro, insulin aspart, and insulin glargine) are the most recent advancement in insulin therapy, attenuating many of the common barriers to traditional insulin use. The use of insulin analogs has provided a more physiologic approach to insulin dosing, allowing a basal/bolus regimen of insulin delivery com- 


\section{Analysis of Cost and Utilization of Health Care Services Before and After Initiation of Insulin Therapy in Patients With Type 2 Diabetes Mellitus}

parable to that of continuous subcutaneous insulin infusion (insulin pump theory). This "poor man's" insulin pump method of intensive insulin therapy has allowed improved glycemic control, while lowering the risk of hypoglycemia, and improving patient convenience compared to traditional insulin therapy. ${ }^{20-23}$ The use of new insulin products, which lessen the clinical barriers to insulin use, may possess an even greater potential to reduce the overall economic burden associated with diabetes management.

Standardizing the pricing for all medical and pharmacy claims was necessary since the database contained members from different health plans with varying benefit designs. Professional and ancillary services were standardized to approximately $120 \%$ of the national Medicare payment level. Facility outpatient services were priced using cost-to-charge ratios. In order to create a standardized pharmacy cost, the average payment schedule (net plan after subtraction of member cost share) was applied to each pharmacy service, based on the National Drug Code and the metric quantity on each prescription claim.

An adequate amount of time was required in order to evaluate the cost and utilization of health care services before and after a patient with type 2 DM started insulin therapy. The 9-month data requirement used for defining this study population was adopted to ensure that a large enough population of patients was identified for the analysis while maintaining an adequate longitudinal study time frame. Member turnover in managed care is at such a rate that it is difficult to enroll a large study cohort with substantially more than 18 months of continuous enrollment when using administrative claims data. On average, $28.2 \%$ of a health plan's membership disenrolls annually, according to the Health Plan Employer Data and Information Set national results. ${ }^{24}$ Of the 215,024 members with type $2 \mathrm{DM}$ in our database, the number of enrollees with 6,9 , or 12 months of data available before and after the start of insulin were $2,254,1,177$, and 325 members, respectively. The 9-month cohort was therefore chosen for this analysis, though consistent results were found when the same analyses were performed on the 6-and 12-month cohorts (data not shown).

The trending analysis individually compared 4 mutually exclusive 60-day postinsulin intervals with the 60-day time period immediately prior to the start of insulin. The authors chose to use the 60-day preinsulin period as a representation of the cost of health care services immediately prior to the initiation of insulin in patients with type $2 \mathrm{DM}$. These costs were then compared to the 4 postinsulin 60-day time intervals to trend costs after the initiation of insulin therapy (Table 5). Consideration was given to analyzing average monthly costs, but, due to the variability in costs on a month-by-month basis, interpretation of the trending results would have been unreliable. The 60-day intervals were selected to reduce the variation that occurs in a month-by-month analysis while still preserving the ability to analyze postinsulin trending information.

Multiple regression analysis was performed to assess the impact of patient age, gender, comorbid disease, and geographic location on the subsequent change in disease-related and total patient costs. Using unadjusted as well as truncated costs and analyzing each cost component (prescription, medical, and facility), no specific variable was found to be consistently significant in affecting health expenditures.

Spending on diabetes care has continued to increase in the United States, due, in part, to the epidemic increase in number of patients with DM. Cost-effective management of diabetes with insulin therapy has been shown to improve glycemic control in poorly controlled type $2 \mathrm{DM}$ patients without adversely affecting quality of life. ${ }^{25}$ Using insurance claims data, the results of this study demonstrate the utility of insulin therapy in reducing long-term health care costs in the management of patients with type $2 \mathrm{DM}$.

\section{Limitations}

Using claims data for retrospective analysis provides several advantages, including access to a large study population with geographic and demographic diversity. The study design attempted to address several potential limitations of using administrative claims data in evaluating patients with type 2 DM. The lower age limit of 18 years was used to restrict the analysis to adult patients, removing any treatment differences that may be present in the pediatric and adolescent patient populations. The upper age limit of 65 years was used to remove the Medicare patient population because their medical benefits are typically different from that of the commercial population, which can limit the ability to capture all relevant claims data. All patients in the study cohort were confirmed to have both medical and pharmacy benefits during the analysis period and were continuously enrolled.

This is a cost and utilization analysis only. The authors acknowledge that outcomes data would provide additional value to the study results. For instance, the ability to identify the patients who attained treatment goals could be helpful in analyzing the cost of effective treatment versus the overall treatment costs that were included in this analysis. Outcomes data, such as laboratory results, are not consistently available as an adjunct to administrative claims and therefore could not be included in this study. The ability to use hemoglobin AlC results, blood pressure measurements, body weight, and lipid levels would add to the results of this study. As most payers and insurers do not capture this information in their claims data, the authors could not report using these data. Other potentially valuable patient characteristics such as body mass index and vital signs at office visits were also unavailable. There is a trend toward more consistent and reliable capture of this information electronically, making efficient access to additional data elements a possibility in future research.

The authors chose to standardize medical and pharmacy costs across the database in an attempt to reduce bias in inter- 


\section{Analysis of Cost and Utilization of Health Care Services Before and After Initiation of Insulin Therapy in Patients With Type 2 Diabetes Mellitus}

pretation of the results. Standardization of prices (health plan costs) might have masked some of the regional variation in preinsulin and postinsulin costs. Any differences uncovered are therefore driven by the utilization factors and the choice of therapy not by variation in health plan costs associated with geographic region or drug or medical benefit design.

The longitudinal time period used for the study was 18 months of continuous enrollment for each patient included in the analysis. This provided a 9-month preinsulin and 9-month postinsulin analytic window to study the differences in cost and utilization before and after the addition of insulin to the drug regimen. The authors recognize the value in using longer time periods, especially when studying chronic diseases such as DM. To expand the analytic time period, though, an alternate study design would be necessary that might impact the practical nature of performing this analysis.

\section{Conclusion}

Initiation of insulin therapy in the management of type $2 \mathrm{DM}$ was associated with an approximate 10\% initial increase in health care expenditures, followed by a consistent and substantial $40 \%$ decrease in subsequent total health care expenditures 9 months following insulin start. This, coupled with the clinical effectiveness insulin offers to many patients with type 2 DM and the progress that has been made in removing the barriers to its use, appears to add support for clinicians to consider insulin therapy earlier in the diabetes treatment algorithm.

To maximize the clinical and economic benefit that insulin can offer patients with type $2 \mathrm{DM}$, clinicians need to determine the optimal time to introduce this treatment option into each patient's regimen. While insulin may be therapeutically superior to oral therapies, its use may also be cost effective by reducing the cost and utilization of health care services in patients with this disease.

\section{DISCLOSURES}

Funding for this research was provided by Aventis Pharmaceuticals and was obtained by author Michael S. Rosenblum. Rosenblum received financial support from Aventis, and author Michael P. Kane is a member of a speakers bureau for Takeda, Aventis, and Pfizer pharmaceutical companies. Rosenblum served as principal author of the study and was responsible for study concept and design. Analysis and interpretation of data and drafting of the manuscript were contributed by both authors. Critical revision of the manuscript was the work of Rosenblum. Statistical expertise was contributed by R. Alan Bowman, PhD, Associate Professor, Union College, Schenectady, NY. Administrative, technical, and/or material support was provided by Bowman and Integrail.

\section{REFERENCES}

1. Steinbrook R. The prescription-drug problem. N Engl J Med. 2002;346:790.

2. Mokdad AH, Ford ES, Bowman BA, et al. Diabetes trends in the U.S. 1990-1998. Diabetes Care. 2000;23:1278-83.

3. Harris MI, Flegal KM, Cowle CC, et al. Prevalence of diabetes, impaired fasting glucose, and impaired glucose tolerance in U.S. adults. The third national health and nutrition examination survey, 1988-1994. Diabetes Care. $1998 ; 21: 518-24$

4. Rodby RA, Firth LM, Lewis EF. An economic analysis of captopril in the treatment of diabetic nephropathy. Diabetes Care. 1996;19:1051-61.
5. Ganz DA, Kuntz KM, Jacobson GA, Avorn J. Cost-effectiveness of 3-hydroxy-3-methylglutaryl coenzyme A reductase inhibitor therapy in older patients with myocardial infarction. Ann Intern Med. 2000;132:780-87.

6. Gray A, Raikou M, McGuire A, et al. Cost effectiveness of an intensive blood glucose control policy in patients with type 2 diabetes: economic analysis alongside randomised controlled trial (UKPDS 41). United Kingdom Prospective Diabetes Study Group. BMJ. 2000;320:1373-78.

7. American Diabetes Association. Diabetes Facts and Figures. Available at www.ada.org/prof/pubs/index.asp. Accessed April 19, 2002.

8. National Diabetes Information Clearing House Diabetes Statistics. National Institute of Diabetes and Digestive and Kidney Diseases. Available at: http://www.niddk.nih.gov /health/diabetes. Accessed April 19, 2002.

9. UK Prospective Diabetes Study (UKPDS). VIII. Study design, progress and performance. Diabetologia. 1991;34:877-90.

10. American Diabetes Association. Economic costs of diabetes in the U.S. in 2002. Diabetes Care. 2003;26:917-32.

11. Selby JV, Ray GT, Zhang D, Colby CJ. Excess costs of medical care for patients with diabetes in a managed care population. Diabetes Care. 1997:20:1396-402.

12. Turner RC, Cull CA, Frighi V, et al. Glycemic control with diet, sulfonylurea, metformin, or insulin in patients with type 2 diabetes mellitus: progressive requirement for multiple therapies (UKPDS 40). JAMA. 1999;281:2005-12.

13. DeFronzo RA. Pharmacologic therapy for type 2 diabetes mellitus. Ann Intern Med. 1999;131:281-303.

14. Edelman SV, Henry RR. Diagnosis and Management of Type II Diabetes, 2nd ed. Berkeley, CA: University of California. 1998.

15. Reaven GM. Role of insulin resistance in human disease. Diabetes. 1988;37:1595-607.

16. Wright A, Burden ACF, Paisey RB, Cull CA, Holman RR. Sulfonylurea inadequacy. Efficacy of addition of insulin over 6 years in patients with type 2 diabetes in the U.K. Prospective Diabetes Study (UKPDS 57). Diabetes Care. 2002;25:330-36.

17. Ellis RP, Pope GC, Iezzoni L, et al. Diagnosis-based risk adjustment for Medicare capitation payments. Health Care Financing Review. 1996;17(3):101-28.

18. Medicare: Physician Fee Schedule for Calendar Year 1998; Payment Policies and Relative Value Unit Adjustments; Final Rule. Federal Register. 1997;62(211):59048-260.

19. SAS Institute Inc. SAS User's Guide: Statistics, 1982 Edition. Cary, NC: SAS Institute, Inc., 1982.

20. Ratner RE, Hirsch IB, Neifing JL, et al. Less hypoglycemia with insulin glargine in intensive insulin therapy for type 1 diabetes. Diabetes Care. 2000;23:639-43.

21. Yki-Jarvinen H, Dressler A, Zieman M, et al. Less nocturnal hypoglycemia and better post-dinner glucose control with bedtime insulin glargine compared with bedtime NPH insulin during insulin combination therapy in type 2 diabetes. Diabetes Care. 2001;23:1130-36.

22. Raskin P, Guthrie RA, Leiter L, Anders R, Jovanovic L. Use of insulin aspart, a fast-acting insulin analog, as the mealtime insulin in the management of patients with type 1 diabetes. Diabetes Care. 2000;23:583-88.

23. Rosenstock J, Park G, Zimmerman J, et al. Basal insulin glargine (HOE901) versus NPH insulin in patients with type 1 diabetes on multiple daily insulin regimens. Diabetes Care. 2000;23:1137-42.

24. Health Plan Employer Data and Information Set. National Results for Selected 2000 HEDIS and HEDIS/CAHPS Measures. Available at http://www.ncqa.org/programs/hedis/stability00.htm. Accessed May 21, 2002.

25. Cost-effectiveness of insulin therapy in the management of type 2 diabetes:DeGrauw WJ, van de Lisdonk EH, van Gerwen WHEM, van den Hoogen HJM, van Weel C. Insulin therapy in poorly controlled type 2 diabetic patients: does it affect quality of life? Br J Gen Pract. 2001;51:527-32. 